\title{
DIGITALPRENEURSHIP IN PANDEMIC ERA AT SMK WIRA HARAPAN, DALUNG, KUTA
}

\author{
${ }^{1}$ J. Wahyu Nugroho, ${ }^{2}$ I Wayan Ruspendi Junaedi, ${ }^{3}$ Natalia Sri Endah Kurniawati, ${ }^{4}$ Ida Bagus \\ Kurniawan, ${ }^{5}$ R. Rulick Setyahadi, ${ }^{6}$ I Made Dwi Wira Ardana, ${ }^{7}$ Gede Deddy Rahmat. \\ ${ }^{1}$ Program Studi D3 Manajemen Pemasaran Fakultas Ekonomika dan Humaniora Universitas Dhyana Pura \\ ${ }^{2}$ Program Studi S1 Manajemen Fakultas Ekonomika dan Humaniora Universitas Dhyana Pura \\ ${ }^{3}$ Program Studi D3 Manajemen Pemasaran Fakultas Ekonomika dan Humaniora Universitas Dhyana Pura \\ ${ }^{4}$ Program Studi D3 Manajemen Pemasaran Fakultas Ekonomika dan Humaniora Universitas Dhyana Pura \\ ${ }^{5}$ Program Studi D3 Manajemen Pemasaran Fakultas Ekonomika dan Humaniora Universitas Dhyana Pura \\ ${ }^{6}$ Program Studi D3 Manajemen Pemasaran Fakultas Ekonomika dan Humaniora Universitas Dhyana Pura \\ ${ }^{7}$ Program Studi D3 Manajemen Pemasaran Fakultas Ekonomika dan Humaniora Universitas Dhyana Pura
}

joshua@undhirabali.ac.id, ruspendijunaedi@undhirabali.ac.id, nataliasriendah@yahoo.com, baguskurniawan@undhirabali.ac.id, $\underline{\mathrm{kp} \_s a t y a a d i @ y a h o o . c o . i d, ~ d w i w i r a 76 @ u n d h i r a b a l i . a c . i d, ~}$ igedededdyrahmat@undhirabali.ac.id

\begin{abstract}
Abstrak
Berbagai dampak yang ditimbulkan dari pandemi ini adalah banyak masyarakat yang kehilangan pekerjaan sehingga pada masa sulit saat ini diharapkan masyarakat mampu untuk kreatif melaksanakan semua kegiatan dari rumah. Berdasarkan hal tersebut, Program Studi Manajemen Pemasaran Digital Universitas Dhyana Pura memandang perlu memberikan pemahaman kepada masyarakat khususnya para murid setingkat SMA/SMK mengenai ilmu manajemen dan penerapannya, sehingga diharapkan mampu memberikan pengetahuan kepada keluarganya yang terdampak pada Covid-19, serta mengambil bagian dalam perubahan menuju new normal. Pengabdian ini sekaligus juga memperkenalkan Program Studi Manajemen Pemasaran Digital Universitas Dhyana Pura. Sasaran yang dituju adalah murid SMA/SMAK dan masyarakat dengan memberikan materi terkait ilmu manajemen. Program ini melibatkan suluruh dosen tetap dan beberapa mahasiswa. Metode pelaksanaan pengabdian kepada masyarakat yang akan dilaksanakan menggunakan media online berupa ceramah dan diskusi yang akan dilaksanakan sebanyak 4 kali dimulai pada bulan Mei hingga Juni 2021. Tindak lanjut kegiatan ini adalah membentuk kelompok usaha dan pendampingan oleh dosen dan mahasiswa.
\end{abstract}

Kata Kunci: Digitalpreneurship, Pandemic Era, SMK Wira Harapan. 


\section{PENDAHULUAN}

\subsection{Analisis Situasi}

Pandemi covid-19 yang dideklarasikan pada 11 Maret 2020 telah mempengaruhi negara-negara di semua benua. COVID-19 atau Penyakit Coronavirus 19 mulai muncul di Wuhan, ibu kota provinsi Hubei di RRC, pada bulan Desember 2019 dan menyebar ke seluruh Asia dan dunia.. Menanggapi perkembangan informasi yang berkaitan dengan Coronavirus Disease 2019 (COVID-19) dan juga mengikuti saran dari Pemerintah Indonesia, pada 16 Maret 2020, beberapa perusahaan atau lembaga mulai menerapkan seruan untuk bekerja dan belajar dari rumah sebagai gerakan social distancing.

Berbagai dampak yang ditimbulkan dari pandemic ini adalah banyak masyarakat yang kehilangan pekerjaan sehingga pada masa sulit saat ini diharapkan masyarakat mampu untuk kreatif melaksanakan semua kegiatan dari rumah. Berdasarkan hal tersebut kami merasa pentingnya memberikan pemahaman kepada masyarakat khususnya para murid setingkat SMA/SMK mengenai ilmu manajemen pemasaran digital dan penerapannya, sehingga diharapkan mampu memberikan solusi kepada keluarganya yang terdampak pada Covid-19 ini.

Program Studi Manajemen Pemasaran Digital Universitas Dhyana Pura memandang perlu mengambil bagian dalam perubahan menuju new normal sehingga membantu memberikan informasi dan peluang kepada masyarakat sekaligus juga memperkenalkan Program Studi Manajemen Pemasaran Digital Universitas Dhyana Pura.

Pada program pengabdian akan melibatkan seluruh dosen tetap manajemen yang berjumlah 6 orang dan 8 orang mahasiswa. Kegiatan berupa seminar online melalui aplikasi google meet dengan memberikan materi dan penerapan ilmu manajemen pemasaran digital :1) Manajemen sumber daya manusia, 2) Manajemen pemasaran dan bisnis digital, 3) Manajemen Keuangan, 4) Manajemen
Kewirausahaan dan operasional yang akan dilaksanakan pada bulan Juni hingga Juli 2020.

Beberapa murid yang tertarik pada bisnis akan dibentuk kelompok usaha yang akan di damping oleh dosen dan mahasiswa sehingga siap bersaing dalam bisnis digital.

\subsection{Tujuan}

Tujuan dari kegiatan ini :

1) Untuk memberikan pengetahuan mengenai ilmu manajemen pemasaran digital sehingga para peserta dalam kegiatan ini memahami tentang penerapan manajemen pemasaran dalam kegiatan usaha dan organisasi

2) Untuk memberikan wawasan mengenai peluang usaha dan cara pengelolaan usaha

3) Untuk memberikan ketrampilan dalam berwirausaha sehingga meningkatkan perekonomian keluarga dan masyarakat pada umumnya

\subsection{Manfaat}

Adapun manfaat dari kegiatan Digital Marketing in Pandemic Era yaitu:

\subsubsection{Bagi insitusi Universitas Dhyana Pura}

Meningkatkan hubungan dengan para stakeholder serta sebagai sarana promosi untuk memperkenalkan Program Studi Manajemen Pemasaran Digital yang ada di Universitas Dhyana Pura kepada masyarakat sebagai orang tua calon mahasiswa dan khususnya kepada murid SMA/SMK yang akan memilih perguruan tinggi.

\subsubsection{Bagi Sekolah Tujuan}

1) Para murid mendapatkan informasi mengenai penerapan ilmu

Ekonomi, Sosial, dan Budaya | 1290 
manajemen pemasaran digital sehingga nantinya diharapkan mampu menjadi manajer atau menciptakan peluang usaha.

2) Para Guru mendapatkan informasi mengenai isu-isu terkini dalam manajemen sehingga mampu menambah wawasan dalam proses pembelajaran

3) Sekolah mendapatkan jejaring untuk program bersama masyarakat dan dunia pendidikan.

\subsubsection{Bagi Dosen}

Pelaksanaan tri darma perguruan tinggi yang ke 3 yakni pengabdian masyarakat, sehingga tugas dan kewajiban terpenuhi dalam peningkatan dan pengembangan karier dosen.

\section{METODE PELAKSANAAN}

Metode pelaksanaan pengabdian kepada masyarakat yang telah dilaksanakan menggunakan media online berupa ceramah dan diskusi tentang Ilmu manajemen pemasaran digital dan diakhir kegiatan, peserta diberikan kesempatan bertanya untuk memperjelas pemahaman tentang materi yang dibahas. Tindak lanjut kegiatan seminar ini akan dibentuk kelompok usaha yang didampingi oleh dosen dan mahasiswa. Adapun table 1 dibawah ini adalah nama - nama dosen sebagai narasumber sekaligus sebagai pendamping (coach) peserta siswa SMK Wira Harapan Dalung.

Tabel 1. Narasumber Pengabdian Masyarakat SMK Wira Harapan

\begin{tabular}{|l|l|l|l|}
\hline $\begin{array}{l}\text { N } \\
\text { o }\end{array}$ & Nama & $\begin{array}{l}\text { Jabat } \\
\text { an }\end{array}$ & $\begin{array}{l}\text { Bidang } \\
\text { Keahlian }\end{array}$ \\
\hline 1 & Dr. J. Wahyu & Ketua & Bisnis \\
& $\begin{array}{l}\text { Nugroho.,S.Kom.,M. M. } \\
\text { Si }\end{array}$ & & Digital \\
\hline
\end{tabular}

\begin{tabular}{|l|l|l|l|}
\hline 2 & $\begin{array}{l}\text { Dr. I Wayan } \\
\text { Ruspendi Junaedi, } \\
\text { SE.,MA. }\end{array}$ & $\begin{array}{l}\text { Angg } \\
\text { ota 1 }\end{array}$ & $\begin{array}{l}\text { Kewirausa } \\
\text { haan }\end{array}$ \\
\hline 3 & $\begin{array}{l}\text { Natalia Sri Endah } \\
\text { Kurniawati.,SE.,M.S } \\
\text { i.Ak }\end{array}$ & $\begin{array}{l}\text { Angg } \\
\text { ota 2 }\end{array}$ & Akuntansi \\
\hline 4 & $\begin{array}{l}\text { Ida Bagus } \\
\text { Kurniawan.,S.Kom., } \\
\text { M.Kom }\end{array}$ & $\begin{array}{l}\text { Angg } \\
\text { ota 3 }\end{array}$ & Komputer \\
\hline 5 & $\begin{array}{l}\text { R. Rulick } \\
\text { Setyahadi.,SE.,M.Si }\end{array}$ & $\begin{array}{l}\text { Angg } \\
\text { ota 4 }\end{array}$ & Perpajakan \\
\hline 6 & $\begin{array}{l}\text { Made Dwi Wira } \\
\text { Ardana, SE., MM }\end{array}$ & $\begin{array}{l}\text { Angg } \\
\text { ota 5 }\end{array}$ & SDM \\
\hline 7 & $\begin{array}{l}\text { I Gede Deddy } \\
\text { Rahmat, SE., MM }\end{array}$ & $\begin{array}{l}\text { Angg } \\
\text { ota 6 }\end{array}$ & Pemasaran \\
\hline
\end{tabular}

\subsection{Peserta}

Peserta dalam kegiatan ini adalah pada guru dan murid di SMK Wira Harapan, sejumlah 50 orang.

\subsection{Waktu Pelaksanaan}

Pelaksanaan Pengabdian Masyarakat ini dilakukan sebanyak 4 kali pelatihan dengan diikuti 5 kali pendampingan kepada peserta yang di bagi dalam kelompok kelompok terbatas, dimulai pada bulan Juni hingga September 2021.

\section{PELAKSANAAN KEGIATAN}

\subsection{Sosialisasi Ke Kepala Sekolah SMK Wira Harapan}

Kegiatan pertama yang dilakukan oleh tim pengabdi adalah membahas proposal yang telah lolos dalam evaluasi tim reviewer dengan mengagendakan pertemuan dengan Kepala Sekolah SMK Wira Harapan untuk sosialisasi kegiatan ini. Dibawah ini adalah kegiatan tim saat melakukan sosialisasi menyampaikan rencana dan maksud tim pengabdi kepada Kepala Sekolah SMK Wira Harapan. 


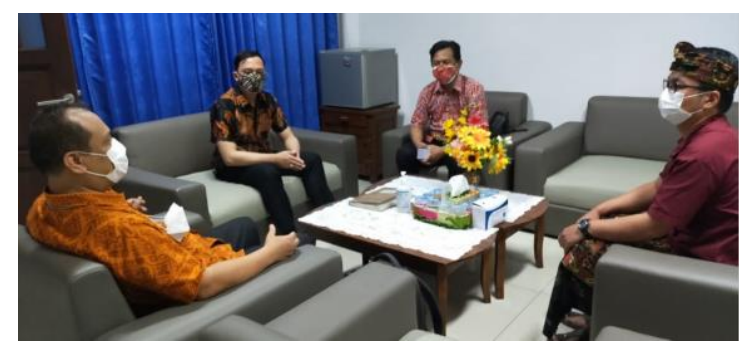

Gambar 1 Bertemu dengan Kepala Sekolah di SMK Wira Harapan

Gambar 1 diatas berlokasi di SMK Wira Harapan Dalung Kuta. Setelah bertemu dengan kepala sekolah, tim membuat group Whats up dengan guru dan siswa SMK Wira Harapan Dalung Kuta yang telah ditunjuk mengikuti pelatihan tersebut. Berdasarkan informasi tersebut, tim pengabdi relative lebih mudah dalam menyampaikan informasi berkenaan dengan kegiatan pelatihan dan pendampingan pengabdian prodi D3 manajemen pemasaran.

\subsection{Pelatihan}

Untuk melakukan pelatihan Pengabdian ini, tim membuat sebuah flyer untuk disebarkan di Group Guru dan siswa SMK Wira Harapan yang akan mengikuti pelatihan agar peserta mengingat akan tanggal tempat dan media yang dipakai. Berikut gambar 2. Flyer kegiatan yang dibuat sekaligus berisi nama kegiatan, Dosen atau narasumber dan Tema Pelatihan. Tema yang diangkat dalam pelatihan ini adalah "Digitalpreneurship, strategi Cuan di Tengah Pandemic". Dengan narasumber sebagai berikut Dr. J. Wahyu Nugroho.,S.Kom.,M.Si, Dr. I Wayan Ruspendi Junaedi, SE.,MA., Natalia Sri Endah Kurniawati.,SE.,M.Si.Ak, Ida Bagus Kurniawan.,S.Kom.,M.Kom, R. Rulick Setyahadi.,SE.,M.Si, Made Dwi Wira Ardana, SE., MM, Gede Dedi Rahmat, SE., MM.

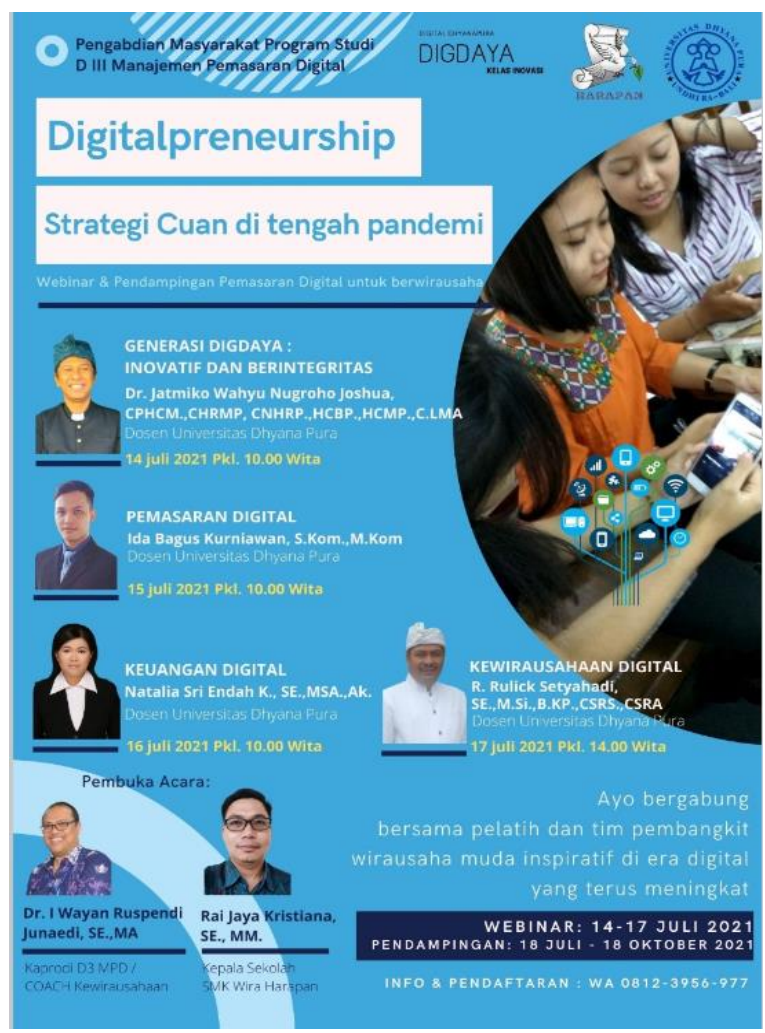

\section{Gambar 2. Flyer Kegiatan Pelatihan Pengabdian Masyarakat SMK Wira Harapan}

Seluruh pelatihan ini dilakukan dengan cara online dengan media zoom, karena masih berlaku PPKM darurat di masa pandemic covid19. Berikut link Zoom yang disiapkan oleh Tim Mahasiswa (Lampiran surat tugas kaprodi d3) yang ikut membantu seluruh program kegiatan ini dari awal sampai akhir pendampingan kegiatan.

Undhira is inviting you to a scheduled Zoom meeting.

Topic: Pengabdian Masyarakat SMK Wira Harapan Dalung Bali

Time: Jul 14, 2021 10:00 Wita

Join Zoom Meeting

https://us06web.zoom.us/j/85737531890?

pwd=ZTISdVNjMkNFbkFPN3JSZ3dFbjhkQT09

Meeting ID: 85737531890

Passcode: undhira

Gambar 3. Link Zoom Pengabdian Masyarakat SMK Wira Harapan 
Link diatas ini tetap dipakai (gambar 3) walaupun harinya berbeda-beda waktunya, yang telah di setting oleh Tim IT Universitas Dhyana Pura (Agus Tomi, S.Kom., M.Kom). Berikut dibawah ini disampaikan jadwal kegiatan pelatihan Pengabdian Masyarakat SMK Wira Harapan dari ntanggal 13-17 Juli 2021.

\subsection{Jadwal Kegiatan}

Kegiatan dilakukan menggunakan media online zoom. Jenis Kegiatan yang dilakukan adalah persiapan, ceramah dan diskusi dengan rincian sebagai berikut (tabel 1.).

Tabel. 1. Jadwal Kegiatan Pelatihan Pengabdian Masyarakat SMK Wira Harapan

\begin{tabular}{|c|c|c|c|c|c|}
\hline $\begin{array}{l}\mathbf{N} \\
\mathbf{0}\end{array}$ & $\begin{array}{c}\text { Hari, } \\
\text { Tanggal }\end{array}$ & $\begin{array}{c}\text { Wakt } \\
\text { u }\end{array}$ & Kegiatan & $\begin{array}{c}\text { Temp } \\
\text { at }\end{array}$ & Penanggung Jawab \\
\hline 1 & $\begin{array}{l}\text { Kamis, } \\
13 \text { Juli } \\
2021\end{array}$ & 09.00 & $\begin{array}{l}\text { Persiapan } \\
\text { pengabdian } \\
\text { masyarakat }\end{array}$ & $\begin{array}{l}\text { Undhir } \\
\text { a }\end{array}$ & $\begin{array}{l}\text { Kaprodi Manajemen } \\
\text { Pemasaran Digital }\end{array}$ \\
\hline 2 & $\begin{array}{l}\text { Jumat, } 14 \\
\text { Juli } 2021\end{array}$ & $\begin{array}{l}10.00 \\
- \\
12.00\end{array}$ & $\begin{array}{l}\text { Sambutan Kaprodi } \\
\text { Manajemen } \\
\text { Pemasaran } \\
\text { Digital, Dekan } \\
\text { dan LPPM } \\
\text { Pengenalan secara } \\
\text { umum Prodi } \\
\text { Manajemen } \\
\text { Pemasaran Digital } \\
\text { Pemaparan Materi } \\
\text { Pemasaran dan } \\
\text { Bisnis Digital } \\
\text { Diskusi }\end{array}$ & $\begin{array}{l}\text { Undhir } \\
\text { a }\end{array}$ & $\begin{array}{ll}\text { 1. } & \text { Kaprodi } \\
& \text { Manajemen } \\
& \text { Pemasaran } \\
& \text { Digital } \\
\text { 2. } & \text { Tim Pengabdi } \\
\text { 3. } & \text { Mahasiswa } \\
& \text { Prodi } \\
& \text { Manajemen } \\
& \text { Pemasaran } \\
& \text { Digital }\end{array}$ \\
\hline 3 & $\begin{array}{l}\text { Senin, } 15 \\
\text { Juli } 2021\end{array}$ & $\begin{array}{l}10.00 \\
- \\
12.00\end{array}$ & $\begin{array}{l}\text { Sambutan Kaprodi } \\
\text { Manajemen } \\
\text { Pemasaran } \\
\text { Digital, Dekan } \\
\text { dan LPPM } \\
\text { Pengenalan secara } \\
\text { umum Prodi } \\
\text { Manajemen } \\
\text { Pemasaran Digital } \\
\text { Pemaparan Materi } \\
\text { Topik SDM } \\
\text { Digital } \\
\text { Diskusi }\end{array}$ & $\begin{array}{l}\text { Undhir } \\
\text { a }\end{array}$ & $\begin{array}{ll}\text { 1. } & \text { Kaprodi } \\
& \text { Manajemen } \\
& \text { Pemasaran } \\
& \text { Digital } \\
\text { 2. } & \text { Tim Pengabdi } \\
\text { 3. } & \text { Mahasiswa Prodi } \\
& \text { Manajemen } \\
& \text { Pemasaran } \\
& \text { Digital }\end{array}$ \\
\hline 4 & $\begin{array}{l}\text { Selasa, } \\
16 \text { Juli }\end{array}$ & $\begin{array}{l}10.00 \\
-\end{array}$ & Sambutan Kaprodi & $\begin{array}{l}\text { Undhir } \\
\text { a }\end{array}$ & $\begin{array}{ll}1 . & \text { Kaprodi } \\
& \text { Manajemen }\end{array}$ \\
\hline
\end{tabular}

\begin{tabular}{|c|c|c|c|c|c|c|}
\hline & 2021 & 12.00 & $\begin{array}{l}\text { Manajemen } \\
\text { Pemasaran } \\
\text { Digital, Dekan } \\
\text { dan LPPM } \\
\text { Pengenalan secara } \\
\text { umum Prodi } \\
\text { Manajemen } \\
\text { Pemasaran Digital } \\
\text { Pemaparan Materi } \\
\text { Topik Keuangan } \\
\text { Diskusi }\end{array}$ & & & $\begin{array}{l}\text { Pemasaran } \\
\text { Digital } \\
\text { Tim Pengabdi } \\
\text { Mahasiswa Prodi } \\
\text { Manajemen } \\
\text { Pemasaran } \\
\text { Digital }\end{array}$ \\
\hline 5 & $\begin{array}{l}\text { Rabu, } 17 \\
\text { Juli } 2021\end{array}$ & $\begin{array}{l}10.00 \\
- \\
12.00\end{array}$ & $\begin{array}{l}\text { Sambutan Kaprodi } \\
\text { Manajemen } \\
\text { Pemasaran } \\
\text { Digital, Dekan } \\
\text { dan LPPM } \\
\text { Pengenalan secara } \\
\text { umum Prodi } \\
\text { Manajemen } \\
\text { Pemasaran Digital } \\
\text { Pemaparan Materi } \\
\text { Topik } \\
\text { Kewirausahaan } \\
\text { Diskusi }\end{array}$ & $\begin{array}{l}\text { Undhir } \\
\text { a }\end{array}$ & $\begin{array}{l}1 . \\
2 . \\
3 .\end{array}$ & $\begin{array}{l}\text { Kaprodi } \\
\text { Manajemen } \\
\text { Pemasaran } \\
\text { Digital } \\
\text { Tim Pengabdi } \\
\text { Mahasiswa Prodi } \\
\text { Manajemen } \\
\text { Pemasaran } \\
\text { Digital }\end{array}$ \\
\hline 6 & $\begin{array}{l}\text { Agustus } \\
\text {-Oktober } \\
2021\end{array}$ & $\begin{array}{l}10.00 \\
- \\
12.00\end{array}$ & $\begin{array}{l}\text { Pendampingan } \\
\text { Kelompok bisnis }\end{array}$ & $\begin{array}{l}\text { SMK } \\
\text { Wira } \\
\text { Harapa } \\
\text { n }\end{array}$ & & $\begin{array}{ll}1 . & \begin{array}{l}\text { Kaprodi } \\
\text { Manajem } \\
\text { en }\end{array} \\
& \begin{array}{l}\text { Pemasara } \\
\text { n Digital }\end{array} \\
2 . & \text { Tim } \\
\text { 3. } & \text { Pengabdi } \\
& \text { Mahasis } \\
& \text { wa Prodi } \\
& \text { Manajem } \\
& \text { en } \\
& \text { Pemasara } \\
& \text { n Digital }\end{array}$ \\
\hline
\end{tabular}

Tabel 1 diatas menggambarkan bahwa kegiatan pelatihan dilakukan sebanyak empat kali, agar siswa SMK Wira Harapan dapat dengan maksimal memiliki pengetahuan yang memadai.

Materi Pemasaran yang disampaikan oleh tim pengabdi salah satu menegaskan bahwa iklan sangat efektif untuk meningkatkan penjualan sebuah usaha (Atmanto, 2014), bahkan iklan pada situs jejaring social. Begitu juga materi tentang Sumber Daya Manusia yang disampaikan oleh tim pengabdi sangat mendukung pendapat dari Leovani, E. 2016. Yang menyatakan bahwa siswa atau masyarakat pada umumnya perlu diberdayakan (empowerment). 
Setelah diberikan pelatihan secara umum, selama 4 hari berturut-turut sekaligus pemberian pengetahuan tentang kewirausahaan, beberapa nama-nama yang mendaftar untuk mendapat pendampingan lebih lanjut dapat dilihat pada table 3 dibawah ini.

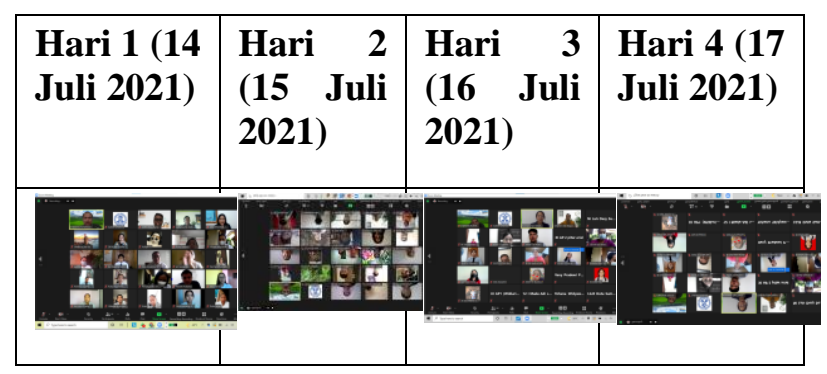

Gambar 4. Foto Peserta saat Pelatihan Berlangsung

Tabel 3 dibawah ini adalah daftar nama peserta dengan nama, jurusan, kelas dan nomer telepon (Hp) dan email address serta rencana bisnisnya.

\section{Tabel 3. Daftar Nama-Nama Peserta Dampingan Pengabdian Masyarakat SMK Wira Harapan}

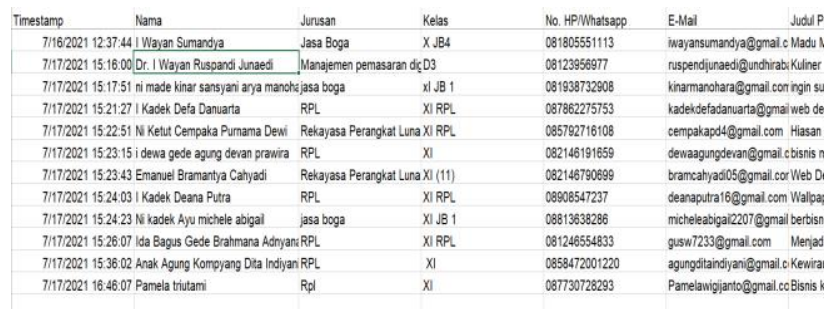

Tabel 3 diatas menunjukkan bahwa dari seluruh peserta diawal yang mengikuti kegiatan hanya sejumlah 12 orang saja yang aktif dan ingin di bimbing dan didampingi oleh tim Pengabdian Masyarakat SMK Wira Harapan, D3 Manajemen Pemasaran Undhira,

Tentu saja nama-nama ini didapat saat pelatihan pertama di sertakan google form untuk diisi bagi siswa yang mau ikut pendampingan lanjutan. Sehingga muncul nama -nama tersebut diatas (tabel 3). Setelah mendapat nama -nama tersebut dengan rincian bisnisnya, maka kembali tim rapat dan menentukan webinar dan membuat flyer kembali dengan inti kegiatan adalah Pendampingan dan Pembuatan bisnis plan. Gambar 3 dibawah ini adalah Flyer yang tim pengabdi buat untuk menginformasikan waktu dampingan secara khusus nama-nama tersebut diatas.
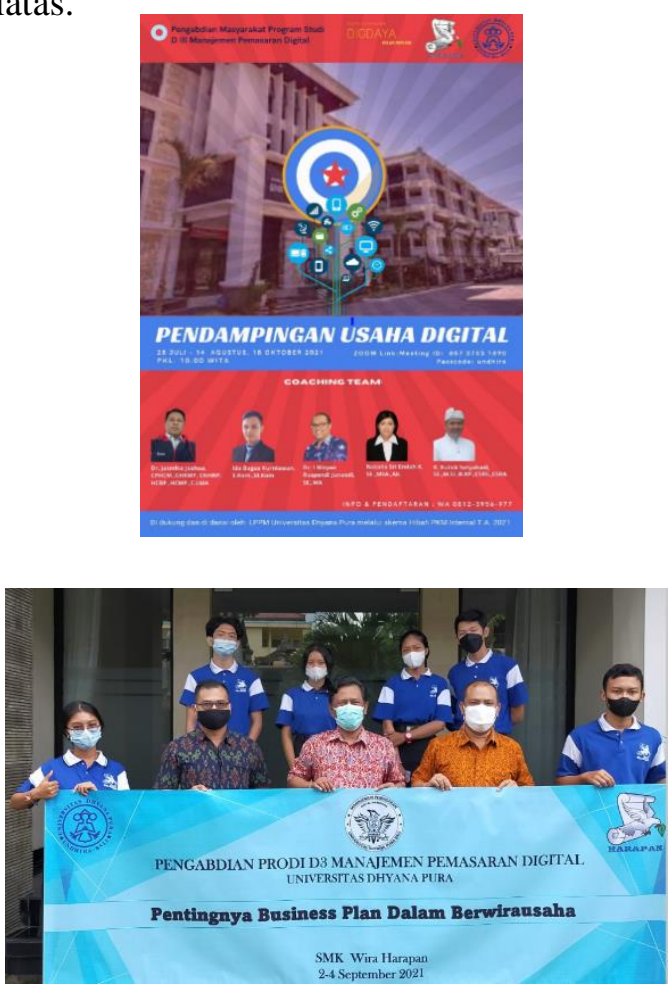

\section{Gambar 5. Flyer Kegiatan Pendampingan Rencana Bisnis.}

Kegiatan Pendampingan usaha dilakukan 5 kali yaitu tanggal 28 Juli 2021, 14 Agustus 2021 (secara online) dan 2-4 September 2021 (ofline). Kegiatan pendampingan ini diberikan untuk mengajarkan bagaimana membuat perencanaan bisnis untuk menjadi start up bisnis. Dibawah ini adalah Foto -Foto kegiatan selama pendampingan yang dilakukan secara offline. 


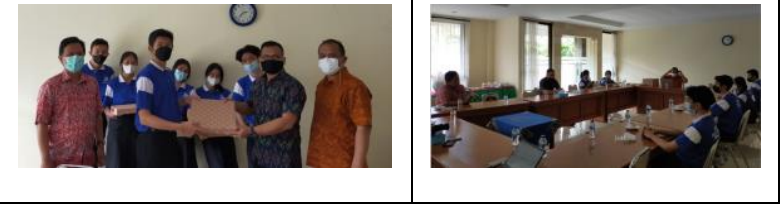

Gambar 6. Foto-Foto Kegiatan Pendampingan Bisnis Plan SMK WIRA Harapan

Yang menjadi poin penting dalam pelatihan ini juga adalah bagaimana siswa atau guru yang memiliki bisnis (pemula) dapat memberikan pelayanan yang prima yang nantinya dapat diimplementasikan secara berkualitas sehingga muncul kepuasan dari pelanggan (Primayani, P.M. dan Reonningrat, N.L.P.A. 2015).

Disamping itu juga dalam materi kewirausahaan yang dipaparkan oleh tim pengabdi, diharapkan bahwa siswa memiliki keberanian dalam berwirausaha (Wijayanti, A.W. dan Insani, S.F. 2016), apalagi sekarang dimasa pandemic covid19 banyak bermunculan usaha-usaha keluarga (kewirausahaan di keluarga).

Outcome dari kegiatan ini adalah ada peningkatan pengetahuan sebelum dan sesudah mengikuti pelatihan. Berikut Grafik 1. Sebelum dan sesudah Pelatihan dan Pendampingan Bisnis Plan SMK Wira Harapan.

\section{Grafik 1. Sebelum dan Sesudah Pelatihan Pengabdian SMK WIRA Harapan}

Jika melihat pernyataan Hapsari, R.D. dan Prakoso, I. 2016, yang mengatakan jika masyarakat Indonesia mampu berwirausaha sampai $10 \%$ dari total penduduk Indonesia maka akan terjadi pertumbuhan ekonomi tingkat provinsi bahkan nasional meningkat.

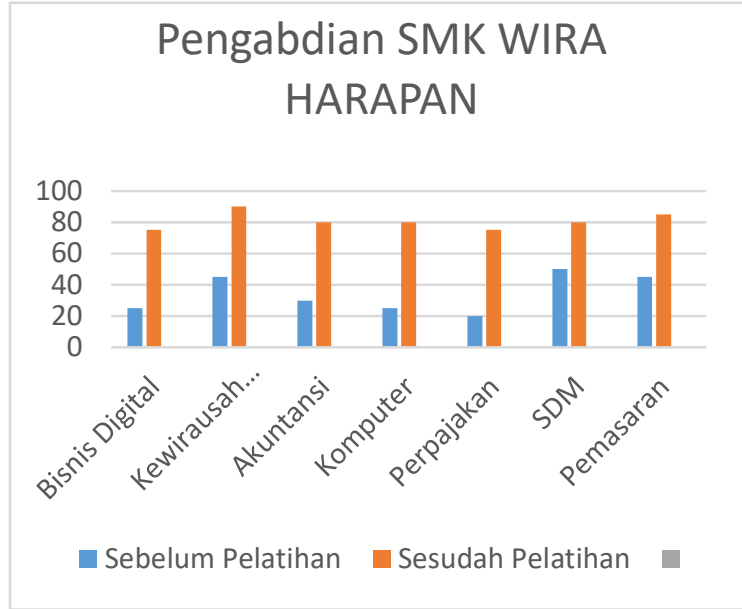

Dalam rangka mengevaluasi program pengabdian prodi $\mathrm{d} 3$ ini, maka anggota mitra harus melaksanakan setiap petunjuk yang telah diberikan oleh para pakar secara konsisten. Tim akan melakukan supervisi dan monitoring ke lokasi secara berkala, sehingga dapat diketahui perkembangan bisnis plan tersebut.

\subsection{Keberlanjutan program}

Dalam rangka keberlanjutan program ini maka mitra SMK Wira ini terus meningkatkan pengetahuan serta skill agar mendapatkan pengetahuan dalam mengelola usahanya secara profesional. Dengan demikian, program ini dapat menciptakan lebih banyak wirausaha baru di sekolah SMK Wira Harapan ini secara khusus dan sekolah sekolah lain secara keseluruhan.

\section{SIMPULAN}

Dalam menyelesaikan masalah di atas, maka solusinya adalah memberikan Pelatihan, pendampingan, penyuluhan, dan monitoring tentang digitalpreneurship yang terdiri dari kewirausahaan, digital, pemasaran, penggunaan teknologi, laporan keuangan, digital bisnis, Sumber daya manusia serta manajemen seperti membuat bisnis plan (perencanaan bisnis). Target program ini bersifat aktual untuk meningkatkan pengetahuan dan wawasan siswa dan guru SMK Wira Harapan semakin lebih baik. 


\section{Ucapan Terimakasih}

Trimakasih kepada LPPM Universitas Dhyana Pura yang telah mendanai pengabdian prodi kami tahun 2021.

\section{DAFTAR PUSTAKA}

Atmanto, A.M. 2014. Efektifitas iklan pada situs jejaring sosial (sebuah studi pada situs facebook.com). Dalam Jurnal of Business and Entrepreneurship. 2 (3): 17-35.

Hapsari, R.D. dan Prakoso, I. 2016. Penanaman modal dan pertumbuhan ekonomi tingkat provinsi di Indonesia. Dalam Jurnal Ekonomi dan Bisnis. XIX (2): 210-227.

Leovani, E. 2016. Implementasi modal pemberdayaan karyawan (Employee empowerment di PT FIFGROUP Tbk cabang Palembang). Dalam Jurnal Manajemen. XX (1): hlm. 241-259.

Primayani, P.M. dan Reonningrat, N.L.P.A. 2015. Analisis kualitas pelayanan terhadap kepuasan pelanggan di PDAM Buleleng cabang Kubutambahan. Dalam Jurnal Manajemen dan Akuntansi STIE Triatma Mulya. 21 (2): hlm. 157-168.

Wijayanti, A.W. dan Insani, S.F. 2016. Analisis anteseden kewirausahaan di perusahaan keluarga. Dalam Jurnal Ekonomi dan Bisnis. XIX (2): hlm. 290-306.

\section{Lampiran 1. Peta Lokasi Wilayah Pengabdian SMK Wira Harapan, Dalung, Kuta}

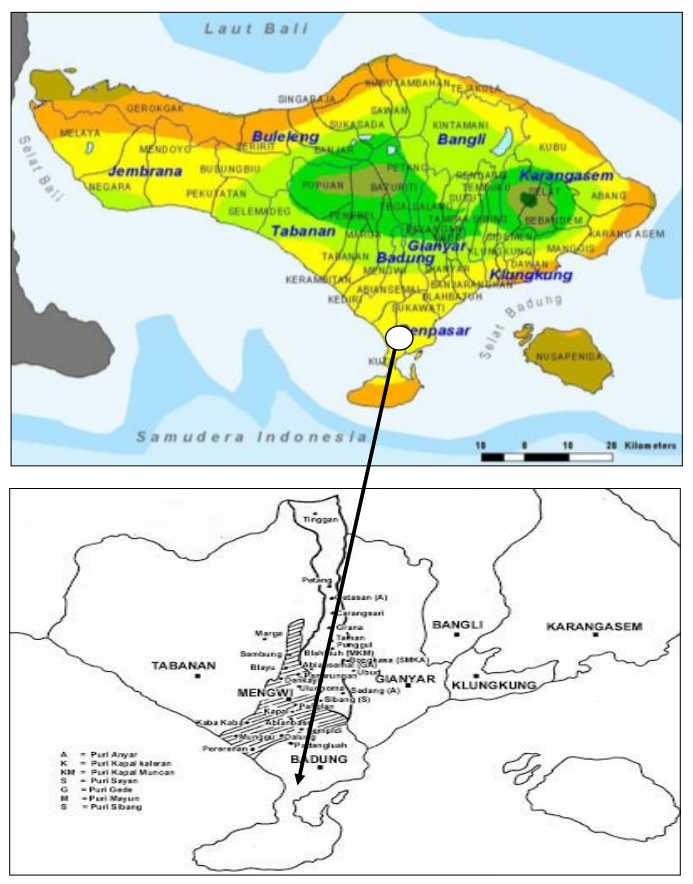


Lampiran 2. Surat Pernyataan Mitra SMK Wira Harapan, Dalung

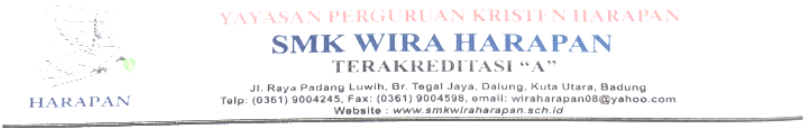

GRAI PERYYTAAN

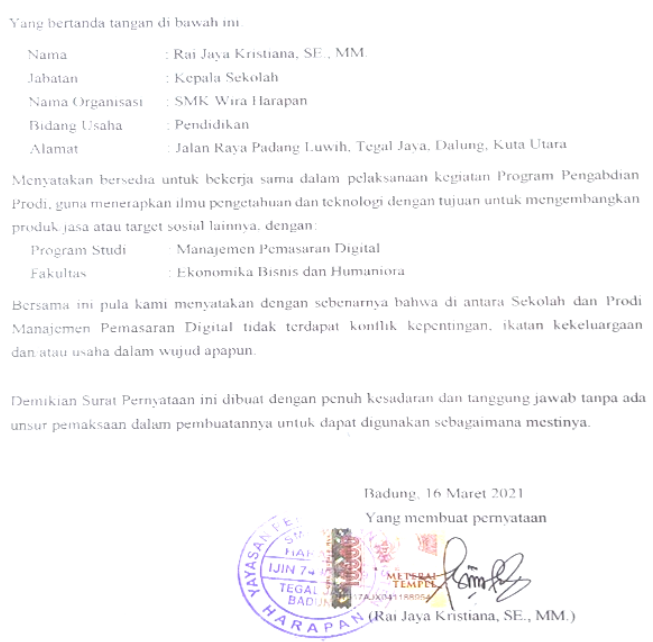

Lampiran 3. Publikasi Berita Elektronik https:channelbali.com/2021/07/17/

Program Studi Manajemem Pemasaran Digital Undhira Berkolaborasi Membentuk Generasi Digdaya $\mid$ CHANNELBALI.com

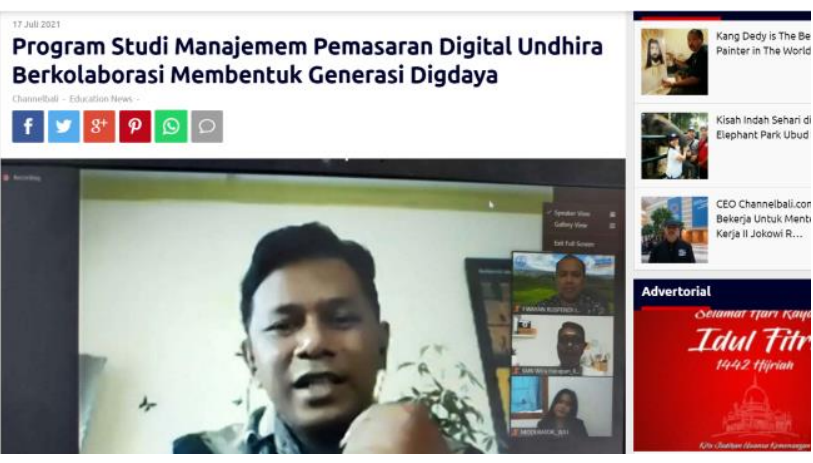

Lampiran 4. Penugasan Mahasiswa dalam Pengabdian SMK Wira Harapan
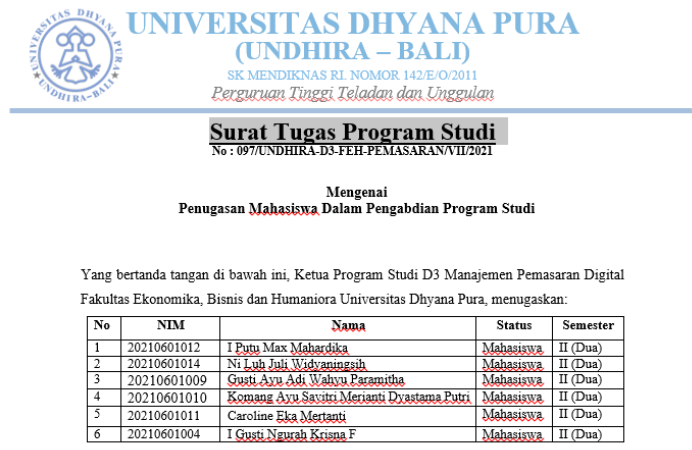

Untuk menjadi Host Zoom dan Moderator/MC dalam Kegiatan Pengabdian Prodi D3 Manajemen Pemasaran Digital Universitas Dhyana Pura dengan tema "Digitalpreneurship Strategi Tetap Tumbuh dan Digdaya di Tengah Pandemi"”, pada tanggal 14 - 17 Juli 2021 Demikian surat tugas ini dibuat. Atas. perhatian dan keriasamanya kami ucapkan terima kasib

Badung, 12 Juli 2021

Program Studi D3 Manajemen Remassaran Digital

Unversitas. Dhyana Rura

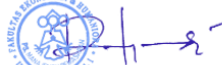

D.I W Wayan Ruspendi Junaedi, SE.MA 